\title{
Operational and Financial Hedging for Exporting Firms *
}

\author{
Kit Pong WONG ${ }^{\dagger}$ \\ University of Hong Kong
}

June 2005

\begin{abstract}
This paper examines the interaction between operational and financial hedging in the context of an internationally competitive but domestically monopolistic firm under exchange rate uncertainty. Operational hedging is modeled by letting the firm make its export decision after it has observed the true realization of the then prevailing spot exchange rate. Financial hedging, on the other hand, is modeled by allowing the firm to trade fairly priced exotic derivatives that are tailor-made for the firm's hedging need. We show that both operational and financial hedging unambiguously entice the firm into producing more. We further derive sufficient conditions under which operational hedging dominates (is dominated by) financial hedging in terms of promoting the firm's optimal output.
\end{abstract}

JEL classification: D21; D81; F31

Keywords: Export flexibility; Exotic derivatives; Production

*I gratefully acknowledge financial support from a grant provided by the University Grants Committee of the Hong Kong Special Administrative Region, China (Project No. AoE/H-05/99). I would like to thank Udo Broll and two anonymous referees for their helpful comments and suggestions. The usual disclaimer applies.

${ }^{\dagger}$ Correspondence to: Kit Pong Wong, School of Economics and Finance, University of Hong Kong, Pokfulam Road, Hong Kong. Tel.: (852) 2859-1044, fax: (852) 2548-1152, e-mail: kpwong@econ.hku.hk (K. P. Wong). 


\title{
Operational and financial hedging for exporting firms
}

\author{
Kit Pong Wong* \\ School of Economics and Finance, University of Hong Kong, Pokfulam Road, Hong Kong
}

\begin{abstract}
This paper examines the interaction between operational and financial hedging in the context of an internationally competitive but domestically monopolistic firm under exchange rate uncertainty. Operational hedging is modeled by letting the firm make its export decision after it has observed the true realization of the then prevailing spot exchange rate. Financial hedging, on the other hand, is modeled by allowing the firm to trade fairly priced exotic derivatives that are tailor-made for the firm's hedging need. We show that both operational and financial hedging unambiguously entice the firm into producing more. We further derive sufficient conditions under which operational hedging dominates (is dominated by) financial hedging in terms of promoting the firm's optimal output.
\end{abstract}

JEL classification: D21; D81; F31

Keywords: Export flexibility; Exotic derivatives; Production

\section{Introduction}

Real options are pervasive in corporate decisions (see Copeland \& Antikarov, 2001). Examples include options to abandon, options to defer, options to expand, options to contract, and many others. In a survey conducted by Triantis and Borison (2001), managers regard real options as an analytical tool, as a language and framing device for investment problems, and as an organizational process.

The purpose of this paper is to study the interaction between operational hedging via real options and financial hedging via customized exotic derivatives. ${ }^{1}$ To this end, we employ the model of an exporting firm under exchange rate uncertainty $\grave{a}$ la Eldor and Zilcha (1987)

\footnotetext{
${ }^{*}$ Tel.: +852-2859-1044; fax: +852-2548-1152.

E-mail address: kpwong@econ.hku.hk.

${ }^{1}$ Wong (2005) examines the effect of abandonment options and exotic hedging on a firm's operating leverage decision.
} 
(see also Wong, 2002, 2003). ${ }^{2}$ The firm is a monopoly in the domestic market but a price taker in a foreign market. The selling prices in both markets are denominated in local currencies. The firm is entitled to operational hedging in that it possesses the flexibility to make its export decision after it has observed the then prevailing spot exchange rate. ${ }^{3}$ Multinational firms, because of their worldwide distribution facilities, fit particularly well the context of export flexibility (see Caves, 1996; Broll, 1999; Broll \& Eckwert, 1999; Wong, 2003).

To examine how the firm's production decision is affected by the interaction between operational and financial hedging, we allow the firm to avail itself of fairly priced exotic derivatives for hedging purposes. We show that the firm optimally tailors its customized exotic derivative contract in a way that the hedged domestic currency profit is stabilized at the expected level, thereby eliminating all exchange rate risk. ${ }^{4}$ When operational hedging via export flexibility is forfeited, we show that the firm optimally cuts down its production if the firm sells exclusively in the domestic market for sufficiently unfavorable spot exchange rates. Otherwise, operational hedging has no effect on output. In contrast, banning the firm from financial hedging always entices the firm into producing less. Finally, we compare the relative efficiency of inducing the firm to produce more by means of operational hedging with that by means of financial hedging. We derive sufficient conditions under which operational hedging dominates (is dominated by) financial hedging in terms of promoting the firm's optimal output. These findings suggest that the interaction between operational and financial hedging is multi-dimensional, making the dominance of one over the other a priori indeterminate.

This paper is closest in the spirit of Wong (2003) who also extends the model of Eldor and Zilcha (1987) to incorporate financial hedging via trading fairly priced exotic derivatives. However, the major concern of Wong's (2003) paper is on the robustness of the

\footnotetext{
${ }^{2}$ Ware and Winter (1988), Broll and Wahl (1997), Broll (1999), Broll and Eckwert (1999), Wong (2001), and Wong and Yick (2004) model export flexibility in a similar way for a globally competitive firm.

${ }^{3}$ Ben-Zvi and Helpman (1992) argue that international transactions are better described by such a sequence of moves. This is supported by the empirical evidence of Magee (1974).

${ }^{4}$ This is analogous to a well-known result in the insurance literature that a risk-averse individual fully insures at an actuarially fair price (see Mossin, 1968).
} 
celebrated separation and full-hedging theorems emanated from the hedging literature (see, e.g., Danthine, 1978; Holthausen, 1979; Feder, Just, \& Schmitz, 1980). The separation theorem states that the production decision of a risk-averse firm is affected neither by the risk attitude of the firm nor by the incidence of the underlying uncertainty should the firm have access to a forward/futures market. The full-hedging theorem states that the firm should completely eliminate its risk exposure by adopting a full-hedge if the forward/futures market is unbiased. This paper, in contrast, focuses on how the interaction between operational and financial hedging affects the production decisions of export-flexible firms, which is absent in Wong (2003).

The rest of this paper is organized as follows. Section 2 delineates our model of an internationally competitive but domestically monopolistic firm under exchange rate uncertainty. To hedge the exchange rate risk, the firm can trade fairly priced exotic derivatives. Section 3 characterizes the firm's optimal output and exotic derivative contract. Section 4 examines the effect of operational hedging via export flexibility on the firm's production decision. Section 5 goes on to examine the effect of financial hedging via trading fairly priced exotic derivatives on the firm's optimal output. Section 6 compares the relative efficiency of operational hedging and financial hedging in enhancing the firm's production. The final section concludes.

\section{The model}

Consider the model of Eldor and Zilcha (1987) wherein an export-flexible firm sells in both the domestic country and a foreign country under exchange rate uncertainty. There is one period with three dates, indexed by $t=0,1$, and 2 . At $t=0$, the firm produces a single output, $q$, according to a cost function, $c(q)$, with $c(0) \geq 0, c^{\prime}(q)>0$, and $c^{\prime \prime}(q)>0$. The riskless rate of interest is known and constant for the period. To simplify notation, we henceforth suppress the known interest factors by compounding all cash flows to their future values at $t=2$. 
We model the exchange rate uncertainty by a positive random variable, $\tilde{e}$, that denotes the prevailing spot exchange rate at $t=2$ and is expressed in units of the domestic currency per unit of the foreign currency. ${ }^{5}$ Let $g(e)$ be the probability density function of $\tilde{e}$ over support $[\underline{e}, \bar{e}]$, where $0<\underline{e}<\bar{e}<\infty$. An alternative way to model the exchange rate uncertainty is to apply the concept of information systems that are conditional probability density functions over a set of signals imperfectly correlated with $\tilde{e}$ (see Eckwert \& Zilcha, 2001, 2003; Drees \& Eckwert, 2003; Broll \& Eckwert, 2005). The advantage of this more general and realistic approach is that one can study the value of information by comparing the information content of different information systems. Since the focus of this paper is not on the value of information, we adopt a simpler structure to save notation.

The firm is export-flexible in that it makes its export (i.e., sales allocation) decision after observing the true realization of $\tilde{e}$ at $t=1$. Conditioned upon the observed spot exchange rate, $e$, the firm sells $q_{d}$ units of its output in the domestic market and exports the rest, $q-q_{d}$, to the foreign country, where $0 \leq q_{d} \leq q$. The firm is a monopoly in the domestic market wherein it faces an inverse demand function, $p_{d}\left(q_{d}\right)$, denominated in the domestic currency, with $p_{d}^{\prime}\left(q_{d}\right)<0$ and $2 p_{d}^{\prime}\left(q_{d}\right)+p_{d}^{\prime \prime}\left(q_{d}\right) q_{d}<0$. The firm is, however, a price taker in the foreign market wherein it sells at a fixed price, $p_{f}$, denominated in the foreign currency and net of any tariffs and/or transportation costs. ${ }^{6}$ Due to the segmentation of the domestic and foreign markets, arbitrage transactions are either impossible or unprofitable, thereby hindering the law of one price. ${ }^{7}$

To hedge the exchange rate risk, the firm avails itself of customized exotic derivatives at $t=0$. We describe the payoff of an exotic derivative contract at $t=2$ by a function, $\phi(e)$, whose functional form is chosen by the firm at $t=0$. To focus on the firm's hedging

\footnotetext{
${ }^{5}$ Throughout the paper, random variables have a tilde $(\sim)$ while their realizations do not.

${ }^{6} \mathrm{It}$ is noteworthy pointing out that the firm faces no exchange rate risk should $p_{f}$ be denominated in the domestic currency. We assume local-currency pricing because it is commonly observed in the real world. In the theoretical ground, Donnenfeld and Zilcha (1991) show that invoicing exports in the importers' currency entails a precommitment to prices so that quantities to be delivered are invariant to realized spot exchange rates. Furthermore, Friberg (1998) shows that setting prices in the importers' currency is optimal when the elasticity of exchange rate pass-through is less than unity, which is the dominant empirical finding in the literature (see Menon, 1995).

${ }^{7}$ The assumption of imperfect arbitrage among national markets is supported by a number of empirical studies of the law of one price. See, e.g., Engel and Rogers $(1996,2001)$ and Parsley and Wei (1996).
} 
motive, vis-à-vis its speculative motive, we assume that the contract is fairly priced in that $\mathrm{E}[\phi(\tilde{e})]=0$, where $\mathrm{E}(\cdot)$ is the expectation operator with respect to $g(e)$. That is, we interpret $\phi(e)$ as net of the price of the contract.

The firm's random profit at $t=2$, denominated in the domestic currency, is given by

$$
\tilde{\pi}=\tilde{e} p_{f}\left(q-q_{d}\right)+p_{d}\left(q_{d}\right) q_{d}-c(q)+\phi(\tilde{e})
$$

The firm is an expected utility maximizer and possesses a von Neumann-Morgenstern utility function, $u(\pi)$, defined over its domestic currency profit at $t=2, \pi$. The firm is risk averse so that $u^{\prime}(\pi)>0$ and $u^{\prime \prime}(\pi)<0 .^{8}$

Figure 1 depicts how the sequence of events unfolds in the model.

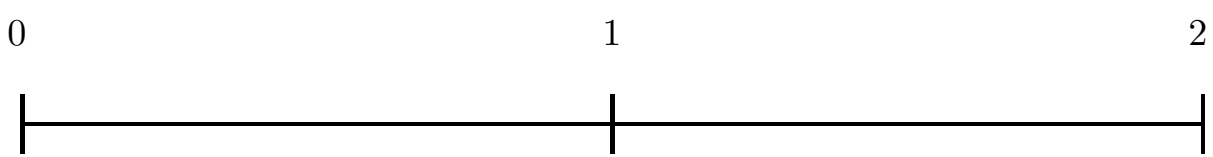

The firm makes its production and hedging decisions.
The firm observes the true realization of the spot exchange rate at $t=2$ and makes its export decision.
The firm sells its output and settles its hedge position.

Figure 1. Time Line

\section{Solution to the model}

We use backward induction to solve the firm's sequential decision problems. At $t=1$,

\footnotetext{
${ }^{8}$ For privately held, owner-managed firms, risk-averse behavior prevails. Even for publicly listed firms, managerial risk aversion (Stulz, 1984), corporate taxes (Smith \& Stulz, 1985), costs of financial distress (Smith \& Stulz, 1985), and capital market imperfections (Stulz, 1990; and Froot, Scharfstein, \& Stein, 1993) all imply a concave objective function for firms, thereby justifying the use of risk aversion as an approximation. See Tufano (1996) for evidence that managerial risk aversion is a rationale for corporate risk management in the gold mining industry.
} 
the firm observes the true realization of the prevailing spot exchange rate at $t=2, e$. Based on this observation, the firm makes its export decision under certainty:

$$
\max _{q_{d}} u\left[e p_{f}\left(q-q_{d}\right)+p_{d}\left(q_{d}\right) q_{d}-c(q)+\phi(e)\right] \text { s.t. } 0 \leq q_{d} \leq q
$$

where $q$ and $\phi(e)$ are taken as given because they have been chosen at $t=0$. The KuhnTucker conditions for program (2) are given by

$$
\begin{aligned}
& p_{d}\left[q_{d}(e, q)\right]+p_{d}^{\prime}\left[q_{d}(e, q)\right] q_{d}(e, q)-e p_{f}-\lambda \leq 0, \\
& q-q_{d}(e, q) \geq 0
\end{aligned}
$$

where $\lambda$ is the Lagrange multiplier and $q_{d}(e, q)$ is the optimal solution. Should $q_{d}(e, q)>0$, condition (3) holds with equality. Similarly, condition (4) holds with equality if $\lambda>0 .{ }^{9}$

To characterize the firm's optimal sales allocation rule, $q_{d}(e, q)$, suppose first that $\lambda>0$. In this case, condition (4) holds with equality and thus $q_{d}(e, q)=q$. It then follows from condition (3) that $p_{d}(q)+p_{d}^{\prime}(q) q>e p_{f}$ or, equivalently,

$$
e<e(q) \equiv \frac{p_{d}(q)+p_{d}^{\prime}(q) q}{p_{f}}
$$

Since $2 p_{d}^{\prime}\left(q_{d}\right)+p_{d}^{\prime \prime}\left(q_{d}\right) q_{d}<0$, we have $e^{\prime}(q)<0$.

Now, suppose that condition (4) holds with strict inequality so that $\lambda=0$. In this case, condition (3) implies that

$$
p_{d}\left[q_{d}(e, q)\right]+p_{d}^{\prime}\left[q_{d}(e, q)\right] q_{d}(e, q)-e p_{f} \leq 0
$$

It is evident that condition (6) must hold with strict inequality for all $e>e(0)=p_{d}(0) / p_{f}$ and thus $q_{d}(e, q)=0$. On the other hand, for all $e \in[e(q), e(0)]$, there exists a unique point, $q_{d}^{*}(e) \in[0, q]$, that solves condition (6) with equality:

$$
p_{d}\left[q_{d}^{*}(e)\right]+p_{d}^{\prime}\left[q_{d}^{*}(e)\right] q_{d}^{*}(e)-e p_{f}=0 .
$$

\footnotetext{
${ }^{9}$ The second-order condition for a maximum is satisfied since $2 p_{d}^{\prime}\left(q_{d}\right)+p_{d}^{\prime \prime}\left(q_{d}\right) q_{d}<0$.
} 
The firm's optimal sales allocation rule, $q_{d}(e, q)$, can be summarized as follows:

$$
q_{d}(e, q)= \begin{cases}q & \text { if } \underline{e} \leq e<\max [\underline{e}, e(q)], \\ q_{d}^{*}(e) & \text { if } \max [\underline{e}, e(q)] \leq e \leq \min [\bar{e}, e(0)], \\ 0 & \text { if } \min [\bar{e}, e(0)]<e \leq \bar{e},\end{cases}
$$

where $e(q)$ is given by Eq. (5) and $q_{d}^{*}(e)$ is given by Eq. (7). Thus, the firm sells exclusively in the domestic market for sufficiently unfavorable spot exchange rates only when $e(q)>\underline{e}$. Alternatively, it exports all of its output to the foreign country for sufficiently favorable spot exchange rates only when $e(0)<\bar{e}$. In the medium range, which could plausibly be the full range when $e(q) \leq \underline{e}<\bar{e} \leq e(0)$, of realized spot exchange rates, the firm sells in both the domestic and foreign markets.

Prior to the resolution of the exchange rate uncertainty, the firm's ex ante decision problem is given by

$$
\max _{q, \phi(e)} \mathrm{E}\{u[\pi(\tilde{e})]\} \quad \text { s.t. } \mathrm{E}[\phi(\tilde{e})]=0
$$

where $\pi(\tilde{e})=\tilde{e} p_{f}\left[q-q_{d}(\tilde{e}, q)\right]+p_{d}\left[q_{d}(\tilde{e}, q)\right] q_{d}(\tilde{e}, q)-c(q)+\phi(\tilde{e})$ and $q_{d}(\tilde{e}, q)$ is defined in Eq. (8). The first-order conditions for program (9) are given by

$$
\begin{aligned}
& \mathrm{E}\left\{u^{\prime}\left[\pi^{*}(\tilde{e})\right]\left\{\max \left[\tilde{e}, e\left(q^{*}\right)\right] p_{f}-c^{\prime}\left(q^{*}\right)\right\}\right\}=0, \\
& u^{\prime}\left[\pi^{*}(e)\right]-\mu^{*}=0 \text { for all } e \in[\underline{e}, \bar{e}],
\end{aligned}
$$

where Eq. (10) follows from Leibniz's rule, $\mu$ is the Lagrange multiplier, and an asterisk $\left(^{*}\right)$ indicates an optimal level. ${ }^{10}$

Since Eq. (11) implies that $\pi^{*}(e)$ is constant for all $e \in[\underline{e}, \bar{e}]$, it then follows from $\mathrm{E}\left[\phi^{*}(\tilde{e})\right]=0$ that

$$
\phi^{*}(e)=\nu^{*}-e p_{f}\left[q^{*}-q_{d}\left(e, q^{*}\right)\right]-p_{d}\left[q_{d}\left(e, q^{*}\right)\right] q_{d}\left(e, q^{*}\right) \text { for all } e \in[\underline{e}, \bar{e}],
$$

\footnotetext{
${ }^{10}$ The second-order conditions for program (9) are satisfied given risk aversion and the strict convexity of $c(q)$.
} 
where $\nu^{*}=\mathrm{E}\left\{\tilde{e} p_{f}\left[q^{*}-q_{d}\left(\tilde{e}, q^{*}\right)\right]+p_{d}\left[q_{d}\left(\tilde{e}, q^{*}\right)\right] q_{d}\left(\tilde{e}, q^{*}\right)\right\}$. In words, the firm tailors the optimal exotic derivative contract, $\phi^{*}(e)$, in a way that its hedged domestic currency profit at $t=2$ is stabilized at the expected level, thereby eliminating all exchange rate risk.

Dividing both sides of Eq. (10) by $u^{\prime}\left[\pi^{*}(e)\right]$, which is invariant to different realizations of $\tilde{e}$, yields

$$
c^{\prime}\left(q^{*}\right)=\mathrm{E}\left\{\max \left[\tilde{e}, e\left(q^{*}\right)\right]\right\} p_{f} .
$$

Since the exchange rate risk is completely eliminated by the optimal exotic derivative contract, the firm chooses its optimal output so as to maximize $\mathrm{E}\left\{\tilde{e} p_{f}\left[q-q_{d}(\tilde{e}, q)\right]+\right.$ $\left.p_{d}\left[q_{d}(\tilde{e}, q)\right] q_{d}(\tilde{e}, q)\right\}-c(q)$, thereby yielding Eq. (13).

\section{The effect of operational hedging on production}

To examine the effect of operational hedging on the firm's optimal production decision, we consider the hypothetical case wherein the firm is obliged to commit to an fixed amount of export irrespective of the true realization of the prevailing spot exchange rate at $t=2$. The firm's random domestic currency profit at $t=2$ as such is given by

$$
\bar{\pi}(\tilde{e})=\tilde{e} p_{f}\left(q-q_{d}\right)+p_{d}\left(q_{d}\right) q_{d}-c(q)+\phi(\tilde{e})
$$

At $t=0$, the firm chooses its level of output, $q$, its level of domestic sales, $q_{d}$, and a fairly priced exotic derivative contract, $\phi(e)$, so as to maximize the expected utility of its random domestic currency profit at $t=2$ :

$$
\max _{q, q_{d}, \phi(e)} \mathrm{E}\{u[\bar{\pi}(\tilde{e})]\} \quad \text { s.t. } 0 \leq q_{d} \leq q \text { and } \mathrm{E}[\phi(\tilde{e})]=0
$$

where $\bar{\pi}(e)$ is defined in Eq. (14).

The Kuhn-Tucker conditions for program (15) are given by

$$
\mathrm{E}\left\{u^{\prime}\left[\bar{\pi}^{0}(\tilde{e})\right]\left[\tilde{e} p_{f}-c^{\prime}\left(q^{0}\right)\right]\right\}=0
$$




$$
\begin{aligned}
& \mathrm{E}\left\{u^{\prime}\left[\bar{\pi}^{0}(\tilde{e})\right]\left[p_{d}\left(q_{d}^{0}\right)+p_{d}^{\prime}\left(q_{d}^{0}\right) q_{d}^{0}-\tilde{e} p_{f}\right]\right\}-\lambda^{0} \leq 0, \\
& q^{0}-q_{d}^{0} \geq 0 \\
& u^{\prime}\left[\bar{\pi}^{0}(e)\right]-\mu^{0}=0 \text { for all } e \in[\underline{e}, \bar{e}],
\end{aligned}
$$

where $\lambda$ and $\mu$ are the Lagrange multipliers and a nought $\left({ }^{0}\right)$ indicates an optimal level. Should $q_{d}^{0}>0$, condition (17) holds with equality. Similarly, condition (18) holds with equality if $\lambda^{0}>0 .{ }^{11}$

Since Eq. (19) implies that $\bar{\pi}^{0}(e)$ is constant for all $e \in[\underline{e}, \bar{e}]$, it then follows from $\mathrm{E}\left[\phi^{0}(\tilde{e})\right]=0$ that

$$
\phi^{0}(e)=[\mathrm{E}(\tilde{e})-e] p_{f}\left(q^{0}-q_{d}^{0}\right) \text { for all } e \in[\underline{e}, \bar{e}]
$$

In words, the firm completely eliminates its exchange rate risk exposure by the optimal exotic derivative contract, $\phi^{0}(e)$, which can be perfectly replicated by a full-hedge via shorting $p_{f}\left(q^{0}-q_{d}^{0}\right)$ units of the unbiased futures contracts.

Dividing both sides of Eq. (16) by $u^{\prime}\left[\bar{\pi}^{0}(e)\right]$, which is invariant to different realizations of $\tilde{e}$, yields

$$
c^{\prime}\left(q^{0}\right)=\mathrm{E}(\tilde{e}) p_{f}
$$

Similarly, we can rewrite condition (17) as

$$
p_{d}\left(q_{d}^{0}\right)+p_{d}^{\prime}\left(q_{d}^{0}\right) q_{d}^{0}-\mathrm{E}(\tilde{e}) p_{f}-\frac{\lambda^{0}}{u^{\prime}\left[\bar{\pi}^{0}(e)\right]} \leq 0
$$

Thus, it follows from condition (22) and the analysis in Section 3 that $q_{d}^{0}=q_{d}\left[\mathrm{E}(\tilde{e}), q^{0}\right]$, where $q_{d}(e, q)$ is defined in Eq. (8). ${ }^{12}$

\footnotetext{
${ }^{11}$ The second-order conditions for program (15) are satisfied given risk aversion and the assumed properties of $c(q)$ and $p_{d}\left(q_{d}\right)$.

${ }^{12}$ Eqs. (20) and (21) are simply the celebrated separation and full-hedging theorems of Danthine (1978), Holthausen (1979), and Feder, Just, and Schmitz (1980).
} 
Proposition 1. Suppose that the export-inflexible firm is allowed to use fairly priced exotic derivatives for hedging purposes. Introducing operational hedging via export flexibility to the firm has a positive (no) effect on output, i.e., $q^{*}>(=) q^{0}$, if $e\left(q^{0}\right)>(\leq) \underline{e}$.

Proof. If $e\left(q^{0}\right) \leq \underline{e}$, Eq. (13) becomes Eq. (21) at $q^{0}$ and thus $q^{*}=q^{0}$. On the other hand, if $e\left(q^{0}\right)>\underline{e}$, the right-hand side of Eq. (13) exceeds $\mathrm{E}(\tilde{e})$ at $q^{0}$ and thus $q^{*} \neq q^{0}$. Since $c^{\prime \prime}(q)>0$ and $e^{\prime}(q)<0$, it follows immediately from Eqs. (13) and (21) that $q^{*}>q^{0}$.

The intuition of Proposition 1 is as follows. Using Eq. (14), we can write Eq. (1) with $q_{d}=q_{d}(e, q)$ as

$$
\pi(e)=\bar{\pi}(e)-\left[p_{d}\left(q_{d}\right)-e p_{f}\right] q_{d}+\left\{p_{d}\left[q_{d}(e, q)\right]-e p_{f}\right\} q_{d}(e, q)
$$

It is evident that the firm's output, $q$, affects its random domestic currency profit at $t=2$ differently with and without operational hedging through the last term on the right-hand side of Eq. (23). Suppose that the firm ignores the marginal effect of its output on this term. Then, Eq. (23) implies that $q^{*}=q^{0}$. If $e\left(q^{0}\right) \leq \underline{e}$, from Eq. (8) we have

$$
q_{d}\left(e, q^{0}\right)= \begin{cases}q_{d}^{*}(e) & \text { if } \underline{e} \leq e \leq \min [\bar{e}, e(0)], \\ 0 & \text { if } \min [\bar{e}, e(0)]<e \leq \bar{e}\end{cases}
$$

which is independent of $q^{0}$. Thus, it follows from Eq. (24) that the marginal effect of the firm's output on $\left\{p_{d}\left[q_{d}(e, q)\right]-e p_{f}\right\} q_{d}(e, q)$ can indeed be ignored at $q=q^{0}$ for all $e \in[\underline{e}, \bar{e}]$. In words, if it is not optimal to sell exclusively in the domestic market even under the worst possible spot exchange rate, introducing operational hedging via export flexibility to the firm does not affect the optimal output.

If $e\left(q^{0}\right)>\underline{e}$, from Eq. (8) we have

$$
q_{d}\left(e, q^{0}\right)= \begin{cases}q^{0} & \text { if } \underline{e} \leq e<e\left(q^{0}\right), \\ q_{d}^{*}(e) & \text { if } e\left(q^{0}\right) \leq e \leq \min [\bar{e}, e(0)], \\ 0 & \text { if } \min [\bar{e}, e(0)]<e \leq \bar{e}\end{cases}
$$


Eq. (25) implies that the marginal effect of the firm's output on $\left\{p_{d}\left[q_{d}(e, q)\right]-e p_{f}\right\} q_{d}(e, q)$ cannot be ignored at $q=q^{0}$ for all $e \in\left[\underline{e}, e\left(q^{0}\right)\right)$, which is equal to $\left[e\left(q^{0}\right)-e\right] p_{f}>0$. Thus, the firm is induced to produce beyond $q^{0}$. In words, if it is optimal to sell exclusively in the domestic market for sufficiently unfavorable spot exchange rates, introducing operational hedging via export flexibility to the firm renders a positive effect on output.

\section{The effect of financial hedging on production}

Now, we want to examine the effect of financial hedging on the firm's optimal production decision. To this end, we consider the hypothetical case wherein the firm is banned from engaging in risk management. That is, we set $\phi(e) \equiv 0$ and thus the firm's random domestic currency profit at $t=2$ is given by

$$
\hat{\pi}(\tilde{e})=\tilde{e} p_{f}\left[q-q_{d}(\tilde{e}, q)\right]+p_{d}\left[q_{d}(\tilde{e}, q)\right] q_{d}(\tilde{e}, q)-c(q),
$$

where $q_{d}(e, q)$ is defined in Eq. (8).

The firm chooses its level of output, $q$, at $t=0$ so as to maximize the expected utility of its random domestic currency profit at $t=2$ :

$$
\max _{q} \mathrm{E}\{u[\hat{\pi}(\tilde{e})]\}
$$

where $\hat{\pi}(\tilde{e})$ is defined in Eq. (26). The first-order condition for program (27) is given by

$$
\mathrm{E}\left\{u^{\prime}\left[\hat{\pi}^{\diamond}(\tilde{e})\right]\left\{\max \left[\tilde{e}, e\left(q^{\diamond}\right)\right] p_{f}-c^{\prime}\left(q^{\diamond}\right)\right\}\right\}=0
$$

where Eq. (28) follows from Leibniz's rule and a diamond $\left(^{\diamond}\right)$ indicates an optimal level. ${ }^{13}$

\footnotetext{
${ }^{13}$ The second-order condition for program (27) is satisfied given risk aversion and the strict convexity of $c(q)$.
} 
Proposition 2. If the export-flexible firm is banned from engaging in risk management, its optimal level of output depends on its risk preferences as well as on the underlying exchange rate uncertainty. Furthermore, introducing fairly priced exotic derivatives to the firm for hedging purposes always entails a positive effect on output, i.e., $q^{*}>q^{\diamond}$.

Proof. The first part of this proposition is evident from equation (28). To prove the second part, we differentiate $\mathrm{E}\{u[\hat{\pi}(\tilde{e})]\}$ with respect to $q$ and evaluate the resulting derivative at $q=q^{*}$ to yield ${ }^{14}$

$$
\left.\frac{\mathrm{d}}{\mathrm{d} q} \mathrm{E}\{u[\hat{\pi}(\tilde{e})]\}\right|_{q=q^{*}}=\operatorname{Cov}\left\{u^{\prime}\left[\hat{\pi}^{*}(\tilde{e})\right], \max \left[\tilde{e}, e\left(q^{*}\right)\right]\right\} p_{f},
$$

where $\hat{\pi}^{*}(\tilde{e})=\tilde{e} p_{f}\left[q^{*}-q_{d}\left(\tilde{e}, q^{*}\right)\right]+p_{d}\left[q_{d}\left(\tilde{e}, q^{*}\right)\right] q_{d}\left(\tilde{e}, q^{*}\right)-c\left(q^{*}\right), \operatorname{Cov}(\cdot, \cdot)$ is the covariance operator with respect to $g(e)$, and we have used Eq. (13). Note that

$$
\frac{\partial}{\partial e} u^{\prime}\left[\hat{\pi}^{*}(e)\right]=u^{\prime \prime}\left[\hat{\pi}^{*}(e)\right] p_{f}\left[q^{*}-q_{d}\left(e, q^{*}\right)\right] \leq 0
$$

since $u^{\prime \prime}(\pi)<0$ and $q_{d}\left(e, q^{*}\right) \leq q^{*}$, and the inequality is strict for all $e \in\left[\max \left[\underline{e}, e\left(q^{*}\right)\right], \bar{e}\right]$. Let $\hat{e}=\mathrm{E}\left\{\max \left[\tilde{e}, e\left(q^{*}\right)\right]\right\}>e\left(q^{*}\right)$. Then, we have

$$
\begin{aligned}
\operatorname{Cov}\left\{u^{\prime}\left[\hat{\pi}^{*}(\tilde{e})\right], \max \left[\tilde{e}, e\left(q^{*}\right)\right]\right\} & =\int_{\underline{e}}^{\bar{e}} u^{\prime}\left[\hat{\pi}^{*}(e)\right]\left\{\max \left[e, e\left(q^{*}\right)\right]-\hat{e}\right\} g(e) \mathrm{d} e \\
& =\int_{\underline{\underline{e}}}^{\bar{e}}\left\{u^{\prime}\left[\hat{\pi}^{*}(e)\right]-u^{\prime}\left[\hat{\pi}^{*}(\hat{e})\right]\right\}\left\{\max \left[e, e\left(q^{*}\right)\right]-\hat{e}\right\} g(e) \mathrm{d} e \cdot(31)
\end{aligned}
$$

From Eq. (30), we have $u^{\prime}\left[\hat{\pi}^{*}(e)\right] \leq(\geq) u^{\prime}\left[\hat{\pi}^{*}(\hat{e})\right]$ if $e>(<) \hat{e}$. Thus, Eq. (31) implies that $\operatorname{Cov}\left\{u^{\prime}\left[\hat{\pi}^{*}(\tilde{e})\right], \max \left[\tilde{e}, e\left(q^{*}\right)\right]\right\}<0$. It then follows from Eqs. (28) and (29) and the strict concavity of $\mathrm{E}\{u[\hat{\pi}(\tilde{e})]\}$ in $q$ that $q^{\diamond}<q^{*}$.

To see the intuition of Proposition 2, we write Eq. (26) as

$$
\hat{\pi}(e)=\mathrm{E}\left\{\tilde{e} p_{f}\left[q-q_{d}(\tilde{e}, q)\right]+p_{d}\left[q_{d}(\tilde{e}, q)\right] q_{d}(\tilde{e}, q)\right\}-c(q)
$$

\footnotetext{
${ }^{14}$ For any two random variables, $\tilde{x}$ and $\tilde{y}$, we have $\operatorname{Cov}(\tilde{x}, \tilde{y})=\mathrm{E}(\tilde{x} \tilde{y})-\mathrm{E}(\tilde{x}) \mathrm{E}(\tilde{y})$.
} 


$$
\begin{aligned}
& +\left\{e p_{f}\left[q-q_{d}(e, q)\right]+p_{d}\left[q_{d}(e, q)\right] q_{d}(e, q)\right. \\
& \left.-\mathrm{E}\left\{\tilde{e} p_{f}\left[q-q_{d}(\tilde{e}, q)\right]+p_{d}\left[q_{d}(\tilde{e}, q)\right] q_{d}(\tilde{e}, q)\right\}\right\} .
\end{aligned}
$$

The expression inside the curly brackets on the right-hand side of Eq. (32) is random and has mean zero. Since the firm is banned from engaging in risk management, this random noise term can only be controlled by varying $q$. Given risk aversion, it is thus optimal for the firm to produce less than $q^{*}$, a result in line with that of Sandmo (1971).

\section{Operational hedging versus financial hedging}

From Propositions 1 and 2, it is evident that operational hedging via export flexibility and financial hedging via trading fairly priced exotic derivatives are complements in terms of promoting the firm's optimal output. However, making both hedging devices available for the firm may sometimes be too costly. It is thus of interest to compare the relative efficiency of inducing the firm to produce by means of operational hedging with that by means of financial hedging. Note that $q^{\diamond}\left(q^{0}\right)$ is the firm's optimal output when it possesses operational (financial) hedging but no financial (operational) hedging. We say that operational hedging dominates (is dominated by) financial hedging in terms of promoting the firm's optimal output if, and only if, $q^{\diamond}>(<) q^{0}$.

To compare $q^{\diamond}$ and $q^{0}$, we differentiate $\operatorname{E}\{u[\hat{\pi}(\tilde{e})]\}$ with respect to $q$ and evaluate the resulting derivative at $q=q^{0}$ to yield

$$
\left.\frac{\mathrm{d}}{\mathrm{d} q} \mathrm{E}\{u[\hat{\pi}(\tilde{e})]\}\right|_{q=q^{0}}=\mathrm{E}\left\{u^{\prime}\left[\hat{\pi}^{0}(\tilde{e})\right]\left\{\max \left[\tilde{e}, e\left(q^{0}\right)\right]-\mathrm{E}(\tilde{e})\right\} p_{f}\right\},
$$

where $\hat{\pi}^{0}(\tilde{e})=\tilde{e} p_{f}\left[q^{0}-q_{d}\left(\tilde{e}, q^{0}\right)\right]+p_{d}\left[q_{d}\left(\tilde{e}, q^{0}\right)\right] q_{d}\left(\tilde{e}, q^{0}\right)-c\left(q^{0}\right)$ and we have used Eq. (21). If the right-hand side of Eq. (33) is positive (negative), it follows from Eq. (28) and the strict concavity of $\mathrm{E}\{u[\hat{\pi}(\tilde{e})]\}$ in $q$ that $q^{\diamond}>(<) q^{0}$.

The right-hand side of Eq. (33) is a priori indeterminate and can either be positive or be negative. We state and prove the following proposition. 
Proposition 3. Operational hedging via export flexibility dominates or is dominated by financial hedging via trading customized exotic derivatives in terms of promoting the exporting firm's optimal output, i.e., $q^{\diamond}>q^{0}$ or $q^{\diamond}<q^{0}$, depending on whether $e\left(q^{0}\right) \geq \mathrm{E}(\tilde{e})$ or $e\left(q^{0}\right) \leq \underline{e}$, respectively.

Proof. If $e\left(q^{0}\right) \geq \mathrm{E}(\tilde{e})$, the right-hand side of Eq. (33) is clearly positive since $\max \left[\tilde{e}, e\left(q^{0}\right)\right] \geq$ $\mathrm{E}(\tilde{e})$. Thus, we have $q^{\diamond}>q^{0}$.

If $e\left(q^{0}\right) \leq \underline{e}$, we write Eq. (33) as

$$
\left.\frac{\mathrm{d}}{\mathrm{d} q} \mathrm{E}\{u[\hat{\pi}(\tilde{e})]\}\right|_{q=q^{0}}=\mathrm{E}\left\{u^{\prime}\left[\hat{\pi}^{0}(\tilde{e})\right][\tilde{e}-\mathrm{E}(\tilde{e})]\right\} p_{f}=\operatorname{Cov}\left\{u^{\prime}\left[\hat{\pi}^{0}(\tilde{e})\right], \tilde{e}\right\} p_{f} .
$$

Since $\partial u^{\prime}\left[\hat{\pi}^{0}(e)\right] / \partial e=u^{\prime \prime}\left[\hat{\pi}^{0}(e)\right] p_{f}\left[q^{0}-q_{d}\left(e, q^{0}\right)\right] \leq 0$, we have $\operatorname{Cov}\left\{u^{\prime}\left[\hat{\pi}^{0}(\tilde{e})\right], \tilde{e}\right\}<0$. Thus, it follows from Eq. (34) that $q^{\diamond}<q^{0}$.

The intuition of Proposition 3 is as follows. If $e\left(q^{0}\right) \geq \mathrm{E}(\tilde{e})$, we have $q_{d}^{0}=q_{d}\left[\mathrm{E}(\tilde{e}), q^{0}\right]=$ $q^{0}$. That means, the firm possessing financial hedging but no operational hedging does not export any of its output so that financial hedging becomes redundant. Operational hedging, on the other hand, is never redundant, thereby rendering its dominance in this case. If $e\left(q^{0}\right) \leq \underline{e}$, Proposition 1 tells us that the firm possessing financial hedging but no operational hedging has already produced at the first-best level, i.e., $q^{0}=q^{*}$. Replacing financial hedging by operational hedging simply resumes the exchange rate risk and thus gives the firm perverse incentives to produce.

In the normal case where $\underline{e}<e\left(q^{0}\right)<\mathrm{E}(\tilde{e})$, the dominance is less clear cut. To see this, we write Eq. (33) as

$$
\begin{aligned}
\left.\frac{\mathrm{d}}{\mathrm{d} q} \mathrm{E}\{u[\hat{\pi}(\tilde{e})]\}\right|_{q=q^{0}}= & \mathrm{E}\left\{u^{\prime}\left[\hat{\pi}^{0}(\tilde{e})\right]\right\}\left\{\mathrm{E}\left\{\max \left[\tilde{e}, e\left(q^{0}\right)\right]\right\}-\mathrm{E}(\tilde{e})\right\} p_{f} \\
& +\operatorname{Cov}\left\{u^{\prime}\left[\hat{\pi}^{0}(\tilde{e})\right], \max \left[\tilde{e}, e\left(q^{0}\right)\right]\right\} p_{f} .
\end{aligned}
$$

The first term on the right-hand side of Eq. (35) is positive because $\mathrm{E}\left\{\max \left[\tilde{e}, e\left(q^{0}\right)\right]\right\} \geq \mathrm{E}(\tilde{e})$, where the equality holds only when $e\left(q^{0}\right) \leq \underline{e}$. This reflects the fact that the expected 
marginal revenue is higher with operational hedging than with financial hedging. However, the second term on the right-hand side of Eq. (35) is unambiguously negative. This is due to the fact that financial hedging eliminates all exchange rate risk but operational hedging removes none. Thus, the interaction between operational and financial hedging is multidimensional, making the relative efficiency of inducing the firm to produce by means of operational hedging to that by means of financial hedging a priori indeterminate.

\section{Conclusions}

In this paper, we have examined the interaction between operational hedging via export flexibility and financial hedging via trading fairly priced exotic derivatives in the context of an internationally competitive but domestically monopolistic firm under exchange rate uncertainty. The firm is export flexible in that it makes its export decision after observing the true realization of the then prevailing spot exchange rate. We have shown that operational hedging entices the firm into producing more if selling exclusively in the domestic market is optimal for sufficiently unfavorable spot exchange rates. Otherwise, operational hedging has no effect on output. In contrast, the effect of financial hedging on output is always positive. Finally, we have examined the relative efficiency of inducing the firm to produce more by means of operational hedging to that by means of financial hedging. We have derived sufficient conditions under which operational hedging dominates (is dominated by) financial hedging in terms of promoting the firm's optimal output. These findings suggest that the interaction between operational and financial hedging is multi-dimensional, making the dominance of one over the other a priori indeterminate.

\section{Acknowledgements}

I gratefully acknowledge financial support from a grant provided by the University Grants Committee of the Hong Kong Special Administrative Region, China (Project No. 
AoE/H-05/99). I would like to thank Udo Broll and two anonymous referees for their helpful comments and suggestions. The usual disclaimer applies.

\section{References}

Ben-Zvi, S., \& Helpman, E. (1992). Oligopoly in segmented markets. In G. M. Grossman (Ed.), Imperfect competition and international trade. Cambridge, MA: MIT Press.

Broll, U. (1999). Export as an option. International Economic Journal, 13, 19-26.

Broll, U., \& Eckwert, B. (1999). Exchange rate volatility and international trade. Southern Economic Journal, 66, 178-185.

Broll, U., \& Eckwert, B. (2005). Transparency in the foreign exchange market and the volume of international trade. Review of International Economics, in press.

Broll, U., \& Wahl, J. E. (1997). Export flexibility and hedging. Bulletin of Economic Research, 49, 205-211.

Caves, R. E. (1996). Multinational enterprise and economic analysis. Cambridge: Cambridge University Press.

Copeland, T., \& Antikarov, V. (2001). Real options: A practitioner's guide. New York, NY: TEXERE LLC.

Danthine, J.-P. (1978). Information, futures prices, and stabilizing speculation. Journal of Economic Theory, 17, 79-98.

Donnenfeld, S., \& Zilcha, I. (1991). Pricing of exports and exchange rate uncertainty. International Economic Review, 32, 1009-1022.

Drees, B., \& Eckwert, B. (2003). Welfare effects of transparency in foreign exchange markets: The role of hedging opportunities. Review of International Economics, 11, 453463.

Eckwert, B., \& Zilcha, I. (2001). The value of information in production economies. Journal 
of Economic Theory, 100, 172-186.

Eckwert, B., \& Zilcha, I. (2003). Incomplete risk sharing arrangements and the value of information. Economic Theory, 21, 43-58.

Eldor, R., \& Zilcha, I. (1987). Discriminating monopoly, forward markets and international trade. International Economic Review, 28, 459-468.

Engel, C., \& Rogers, J. H. (1996). How wide is the border? American Economic Review, $86,1112-1125$.

Engel, C., \& Rogers, J. H. (2001). Violating the law of one price: Should we make a Federal case out of it? Journal of Money, Credit and Banking, 33, 1-15.

Feder, G., Just, R. E., \& Schmitz, A. (1980). Futures markets and the theory of the firm under price uncertainty. Quarterly Journal of Economics, 94, 317-328.

Friberg, R. (1998). In which currency should exporters set their prices? Journal of International Economics, 45, 59-76.

Froot, K. A., Scharfstein, D. S., \& Stein, J. C. (1993). Risk management: Coordinating corporate investment and financing policies. Journal of Finance, 48, 1629-1658.

Holthausen, D. M. (1979). Hedging and the competitive firm under price uncertainty. American Economic Review, 69, 989-995.

Magee, S. P. (1974). U. S. import prices in the currency-contract period. Brookings Papers on Economic Activity, 1, 117-164.

Menon, J. (1995). Exchange rate pass-through. Journal of Economic Surveys, 9, 197-231.

Mossin, J. (1968). Aspects of rational insurance purchasing. Journal of Political Economy, $76,553-568$.

Parsley, D. C., \& Wei, S. J. (1996). Convergence to the law of one price without trade barriers or currency fluctuations. Quarterly Journal of Economics, 111, 1211-1236.

Sandmo, A. (1971). On the theory of the competitive firm under price uncertainty. American Economic Review, 61, 65-73. 
Smith, C. W., \& Stulz, R. M. (1985). The determinants of firms' hedging policies. Journal of Financial and Quantitative Analysis, 20, 391-405.

Stulz, R. M. (1984). Optimal hedging policies. Journal of Financial and Quantitative Analysis, 19, 127-140.

Stulz, R. M. (1990). Managerial discretion and optimal financial policies. Journal of Financial Economics, 26, 3-27.

Triantis, A., \& Borison, A. (2001). Real options: State of the practice. Journal of Applied Corporate Finance, 14, 8-24.

Tufano, P. (1996). Who manages risk? An empirical examination of risk management practices in the gold mining industry. Journal of Finance, 51, 1097-1137.

Ware, R., \& Winter, R. (1988). Forward markets, currency options and the hedging of foreign exchange risk. Journal of International Economics, 25, 291-302.

Wong, K. P. (2001). Currency hedging for export-flexible firms. International Economic Journal, 15, 165-174.

Wong, K. P. (2002). Export-flexible firms and forward markets. International Economic Journal, 16, 81-95.

Wong, K. P. (2003). Export flexibility and currency hedging. International Economic Review, 44, 1295-1312.

Wong, K. P. (2005). Operating leverage and the interaction between abandonment options and exotic hedging. Journal of Derivatives Accounting, 2, 87-96.

Wong, K. P., \& Yick, H. Y. (2004). Currency options and export-flexible firms. Bulletin of Economic Research, 56, 379-394. 